\title{
Numerical analysis of ballastless asphalt tracks subjected to dynamic loads
}

Bose, T.; Zania, V.; Levenberg, E.

Published in:

Challenges and Innovations in Geomechanics

Link to article, DOI:

10.1007/978-3-030-64518-2_30

Publication date:

2021

Document Version

Peer reviewed version

Link back to DTU Orbit

Citation (APA):

Bose, T., Zania, V., \& Levenberg, E. (2021). Numerical analysis of ballastless asphalt tracks subjected to dynamic loads. In Challenges and Innovations in Geomechanics: IACMAG 2021 (pp. 249-257). Springer. Lecture Notes in Civil Engineering Vol. 126 https://doi.org/10.1007/978-3-030-64518-2 30

\section{General rights}

Copyright and moral rights for the publications made accessible in the public portal are retained by the authors and/or other copyright owners and it is a condition of accessing publications that users recognise and abide by the legal requirements associated with these rights.

- Users may download and print one copy of any publication from the public portal for the purpose of private study or research.

- You may not further distribute the material or use it for any profit-making activity or commercial gain

- You may freely distribute the URL identifying the publication in the public portal

If you believe that this document breaches copyright please contact us providing details, and we will remove access to the work immediately and investigate your claim. 


\title{
Numerical analysis of ballastless asphalt tracks subjected to dynamic loads
}

\author{
T. Bose, V. Zania** and E. Levenberg \\ Department of Civil Engineering, Technical University of Denmark \\ Nordvej, Building 119, Kgs. Lyngby 2800, (Denmark) \\ vaza@byg.dtu.dk*
}

\begin{abstract}
This study presented the results of numerical analyses for a ballastless asphalt track. The asphalt layer was modelled as a linear viscoelastic (LVE) solid that was resting on an unbound granular layer (UGL) simulated as a non-linear (stress-state dependent) elastic medium. The mechanical properties of these layers were calibrated from laboratory element tests. For a given structural arrangement, the model was interrogated under a vertical impulse load to assess the sensitivity of selected responses to temperature and to the initial compaction-induced horizontal stresses in the UGL. It was found that horizontal tensile strains at the bottom of the asphalt layer, vertical stresses below the UGL, and vertical surface accelerations were all very sensitive to temperature level. The vertical surface accelerations were also found to be sensitive to the level of compaction-induced stresses in the UGL. In contrast, the other two responses exhibited a moderate dependency on the latter stresses. The results from this numerical study provide a better overall understanding on the mechanical behaviour of ballastless asphalt tracks.
\end{abstract}

Keywords: Ballastless asphalt track, Compaction induced stress, Dynamic analysis, Finite element model, Temperature.

\section{Introduction}

Over the years, the traffic in the railway network has increased in terms of speed, axle loads and frequency of the trains. In order to adapt to this, the design of the railway tracks has evolved accordingly. Instead of conventional ballasted tracks, high speed networks are increasingly being built with ballastless tracks, mainly concrete slab tracks to date. Lately, attention is being paid to another type of ballastless track made of asphalt concrete. The use of asphalt in railway tracks is not recent and it has been used as a secondary support for the main load bearing layers, both ballast and concrete slab tracks (Rose and Souleyrette, 2014; Yang et al. 2015). Nevertheless, ballastless tracks based on asphalt are still quite rare, with only a few known field applications, e.g., some tunnel sections in Germany (Rose and Souleyrette, 2014). The mechanical behavior of railway tracks has been extensively investigated by means of numerical modelling. The early 
modelling approaches idealized rails as infinite beams and tracks as a Winkler foundation, either elastic (Auersch, 1996) or viscoelastic (Vostroukhov, 2003). Later, the subgrade was integrated with the traditional models as an elastic or viscoelastic half-space (Knothe and $\mathrm{Wu}, 1998)$. Subsequently, a variety of problems were investigated, i.e., track vibrations, stresses and displacements within the track, and modal analysis of different track components employing several numerical methods, of which the finite element method (FEM) was widely applied (Galvín et al. 2010; Powrie et al. 2001; Poveda et al. 2015).

Similar studies on ballastless asphalt tracks are quite limited. Huang et al. 1987 developed a FEM based code to analyze asphalt tracks wherein the substructure was modeled as a multilayered elastic system and the rails and sleepers as finite beams connected by linear springs (representing rail-pads). Design charts for asphalt railway tracks were suggested based on empirical equations reflecting failure criteria commonly adopted in highway pavements. In recent years, full-scale test sections were built to evaluate the performance of ballastless asphalt tracks under different intensities of stationary loads (Lee et al. 2016). Later, Lee et al. 2019 conducted field studies in which a test track was built outdoors and effects of seasonal temperature variation on track responses were assessed. As part of this study, a 3-D FEM model was developed in which the asphalt layers were modeled as linear viscoelastic (LVE) solids. Only quasi-static analysis was performed considering distributed loads over the rails. The calculated responses showed a poor match when compared to field measurements.

Subsequently, a numerical model was developed as part of a research project to investigate the mechanical behaviour of ballastless asphalt tracks. The purpose was to mimic a full-scale, limited size test section of an asphalt track which was built inside a steel box and tested indoors. The numerical model and the sensitivity of selected model responses on temperature and compaction stresses are presented herein.

\section{Finite element model}

A 3-D FE model (Fig. 1) of the asphalt track mockup ( $4.0 \mathrm{~m}$ long and $2.2 \mathrm{~m}$ wide) was developed with the commercial program ABAQUS. From bottom up, it includes: (a) $0.025 \mathrm{~m}$ thick mat that simulates the cumulative effects of subgrade and subballast, (b) $0.275 \mathrm{~m}$ thick unbound granular layer (UGL), (c) $0.280 \mathrm{~m}$ thick asphalt layer, and (d) three wide concrete sleepers (used in the GETRAC A3 system) at $0.60 \mathrm{~m}$ spacing, including a $7 \mathrm{~mm}$ thick geotextile attached at the bottom. The sleepers are $2.40 \mathrm{~m}$ long and $0.57 \mathrm{~m}$ wide at the base and the geotextile is attached at the two ends of the sleeper in contact with the asphalt top surface over an area of $1.00 \mathrm{~m} \times 0.57 \mathrm{~m}$. The boundary conditions applied in the model were similar to the mockup whereby: (i) the bottom was completely constrained, (ii) the sides along the mat and the UGL were restricted from moving in the direction of their respective normal, and (iii) the sides along the asphalt layer were free. Displacement compatibility was enforced in the interfaces between the successive layers. The finite domain was discretized using eight noded linear brick elements with an average element size of $50 \mathrm{~mm}$. A finer mesh was adopted close to the 
loading areas. Table 1 lists the input material parameters considered for the modelling. The material properties of the asphalt layer and the UGL were calibrated from laboratory element tests.

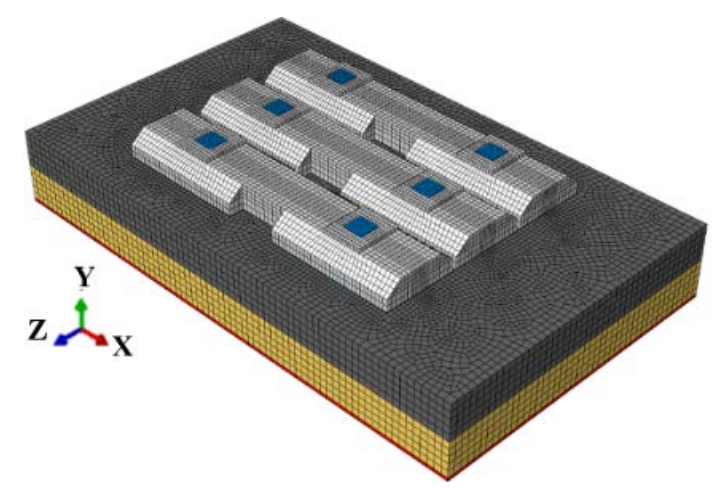

Fig. 1 3-D Finite element model of a ballastless asphalt track mockup (For boundary conditions, see text)

Table 1 Material properties of the different model entities

\begin{tabular}{lcccc}
\hline $\begin{array}{l}\text { Model } \\
\text { entity }\end{array}$ & $\begin{array}{c}\text { Young's modu- } \\
\text { lus (MPa) }\end{array}$ & $\begin{array}{c}\text { Poisson’s } \\
\text { ratio (-) }\end{array}$ & $\begin{array}{c}\text { Density } \\
\left(\mathrm{kg} / \mathrm{m}^{3)}\right.\end{array}$ & $\begin{array}{c}\text { Damping } \\
\text { ratio (\%) }\end{array}$ \\
\hline Rail pad & 13 & 0.40 & 800 & 5 \\
Sleeper & 32,000 & 0.20 & 2500 & 3 \\
Geotextile & 1.2 & 0.15 & 900 & 7 \\
UGL & Eq. (1) & 0.35 & 2286 & 5 \\
Asphalt & Fig. 2a & 0.40 & 2438 & - \\
Mat & 46 & 0.48 & 990 & 5 \\
\hline
\end{tabular}

The Young's modulus of the mat was taken as in the technical specifications, while the rail-pad and the geotextile were obtained from separate tests. The asphalt layer was modelled as a LVE solid with a Prony series expansion of the relaxation modulus (Fig. 2a), obtained from laboratory tests. The UGL was modelled as nonlinear elastic with a bulk stress dependent resilient modulus $\left(M_{r}\right)$ as proposed by Seed et al. 1967:

$$
M_{r}=k_{1} P_{a}\left(\frac{-\sigma_{Y, 0}[1+2 K]+p}{P_{a}}\right)^{k_{2}}
$$

where $k_{1}$ and $k_{2}$ are regression constants obtained from laboratory tests to be 1345 and 0.64 respectively, and $P_{a}$ is the atmospheric pressure. $\sigma_{Y, 0}$ is the initial vertical stress at any point in the UGL resulting from the combined weight of the sleepers (approximated as a uniform pressure over the area), asphalt layer, and the UGL itself. The initial horizontal stresses $\left(\sigma_{X, 0}, \sigma_{Z, 0}\right)$ are the residual stresses induced during UGL compaction, which are unknown and are expressed as a factor of the vertical stress in terms of the 
parameter $K$ ( $\left.\sigma_{X, 0}=\sigma_{Z, 0}=K \sigma_{Y, 0}\right)$ which is the at-rest earth pressure coefficient. $p$ is the bulk stress at any point in the UGL induced only by external loads:

$$
p=-\left(\sigma_{X}+\sigma_{Y}+\sigma_{Z}\right)
$$

where, $\sigma_{X}, \sigma_{Y}$ and $\sigma_{Z}$ are normal stresses along $\mathrm{X}, \mathrm{Y}$ and $\mathrm{Z}$ directions (see Fig. 1). Incorporation of the material model described in Eq. (1). into ABAQUS was done through a user-defined subroutine USDFLD. Rayleigh damping was assigned to approximate an almost constant value of damping ratio within the frequency range of interest. The damping ratio was chosen based on ranges available in literature. As the asphalt layer has dissipation sources as part of the material model (LVE), additional damping was not considered. The sign convention adopted is as follows: tensile stresses and strains are positive and upwards load and displacement is positive.

\section{Sensitivity analyses}

In the numerical model, vertical loads were applied as uniformly distributed stress on top of the two rail-pads of the middle sleeper. The load function is as shown in Fig. 2b, split into half on each of the two rail-pads. Nonlinear implicit dynamic analyses were performed utilizing small time increments, verified to ensure that the evolution of $M_{r}$ with the stress level follows Eq. (1).
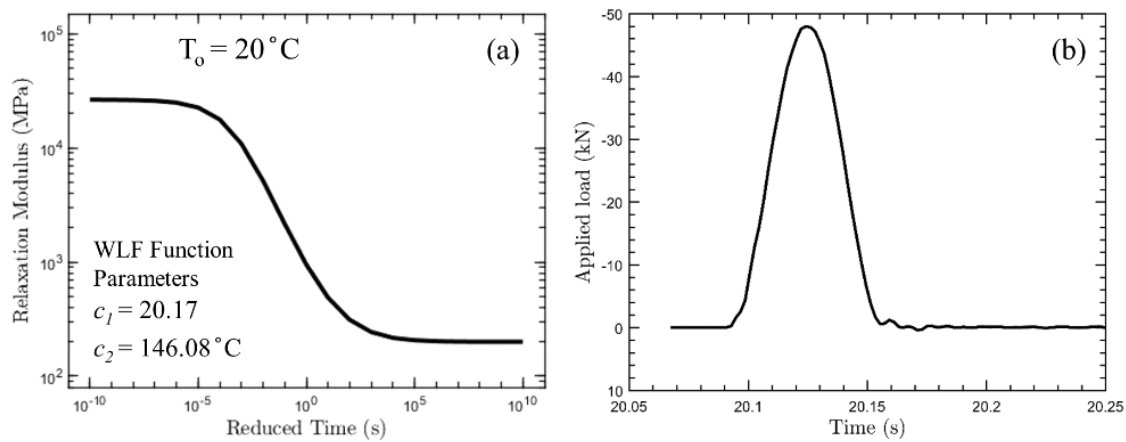

Fig. 2 (a) Relaxation modulus of the asphalt concrete (b) Vertical load history applied to the middle sleeper

The first set of sensitivity analyses involved three temperature levels: $0{ }^{\circ} \mathrm{C}, 22{ }^{\circ} \mathrm{C}$, and $35^{\circ} \mathrm{C}$; each assumed uniform for the whole model. The temperature of $22^{\circ} \mathrm{C}$ was chosen because it corresponds to the neutral track temperature in Denmark. The lower and upper bounds were chosen as representative of winter and summer conditions. The second set of sensitivity analyses involved three values for the parameter $K: 1,4$, and 8 . The upper bound on $K$ was based on keeping it lower than the passive earth pressure coefficient, assuming an internal friction angle of $51^{\circ}$. 


\section{Results and discussions}

Presented in Fig. 3 is a contour plot of the vertical stress distribution in the $\mathrm{X}-\mathrm{Y}$ plane through the model center for $T=22{ }^{\circ} \mathrm{C}$ and $K=1$. The stresses shown are here are excluding the self-weight and the time instant being presented corresponds to the peak load in Fig. 2b. For visual clarity only the track substructure is displayed, extending downwards from the asphalt surface. Compressive stresses are observed on the asphalt surface occurring just below the geotextile locations (loaded areas); these are fairly uniform with a magnitude of around $40 \mathrm{kPa}$. At the middle (in-between the geotextiles), the surface is essentially unloaded. The stresses gradually decrease with depth approaching a peak value at the bottom of the UGL (top of mat) of approximately $45 \%$ of the peak surface stress. Presented in Figs. $4 \mathrm{a}$ and $4 \mathrm{~b}$ are contour plots of horizontal strain distribution at the bottom of the asphalt layer in the $\mathrm{X}-\mathrm{Z}$ plane for $T=22{ }^{\circ} \mathrm{C}$ and $K=1$. The time instant being presented corresponds to when the peak strains occur, which is at a delay from the occurrence of the peak load owing to the VE behaviour of the asphalt layer. Along the $\mathrm{X}$ direction, the bending of the asphalt layer results in tensile strains below the loaded areas and compressive strains at the middle. Along the $\mathrm{Z}$ direction, tensile strains occur below the loaded sleeper and compressive strains below the adjacent ones. The peak tensile strain in the $\mathrm{Z}$ direction is about $100 \%$ higher than that in the $\mathrm{X}$ direction.

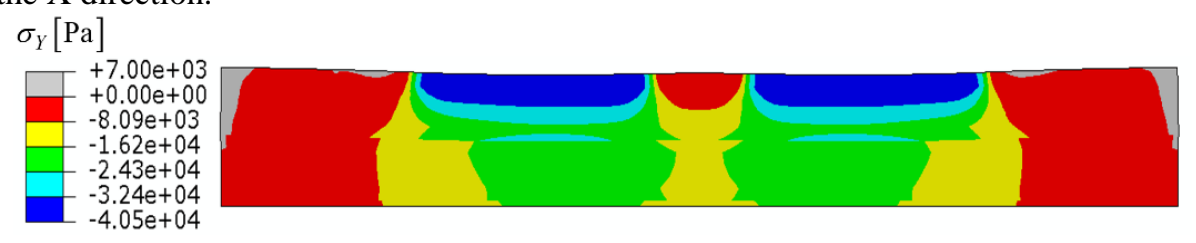

Fig. 3 Contour plot showing vertical stress distribution along depth for a longitudinal section through model center $\left[K=1, T=22^{\circ} \mathrm{C}\right]$

The sensitivity of selected responses to the temperature variation has been presented in Figs. 5 and 6 (assuming $K=1$ ). Fig. 5a illustrates the vertical stress history below the UGL (i.e., on top of the mat) at a location where the peak compressive stress occurs. The three curves in the image follow the overall shape of the applied load (see Fig. 2b) and the peak stresses show an increase with rise in temperature. This can be attributed to the asphalt layer which has a lower stiffness at higher temperatures resulting in increased stresses within the track. Fig. 5b shows the vertical acceleration history of a location that is along the track center line and at the middle of the sleepers (on the asphalt surface). The peak accelerations (upwards) increase from $0.47 \mathrm{~m} / \mathrm{s}^{2}$ to $0.8 \mathrm{~m} / \mathrm{s}^{2}$ as the temperature increases. This is associated with the higher vertical displacements occuring with rising temperatures. It is observed that after unloading (at around $20.15 \mathrm{~s}$ ), the system vibrates at its fundamental frequency, which is calculated to be $73 \mathrm{~Hz}$. The subsequent acceleration peaks in this vibration mode show a gradual decay owing to the associated overall model damping. Fig. 6 illustrates the horizontal tensile strain history at the bottom of the asphalt layer at location where the peak strains occur. The overall shape of the curves follow the load with a pronounced time dependent strain recovery 
occuring at higher temperatures. The peak strain magnitudes are very sensitive to the change in temperature. From a reference state of $22^{\circ} \mathrm{C}$, lowering of temperature to $0^{\circ} \mathrm{C}$, decreases the strains by $70 \%$, while, increase of temperature to $35{ }^{\circ} \mathrm{C}$, increases the strains by $110 \%$ (both along $\mathrm{X}$ and $\mathrm{Z}$ directions).
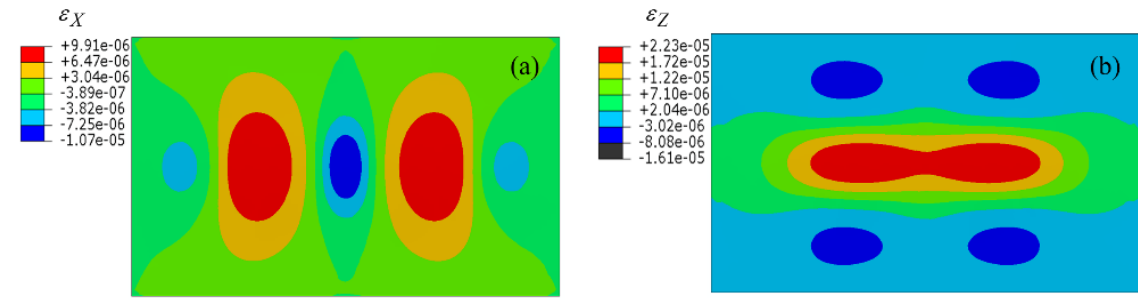

Fig. 4 Contour plots showing horizontal strain distribution at bottom of asphalt layer along (a) X direction and, (b) $\mathrm{Z}$ direction $\left[K=1, T=22^{\circ} \mathrm{C}\right]$.
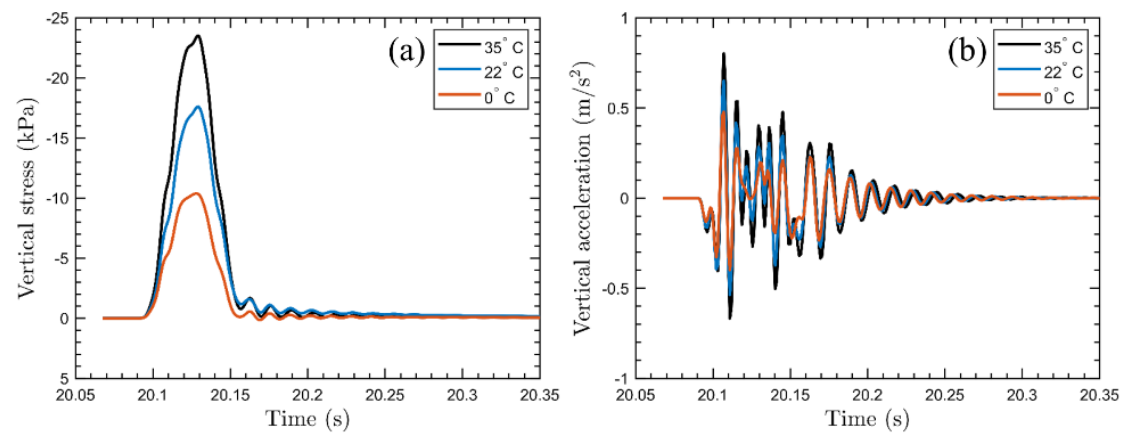

Fig. 5 Influence of temperature on time history of: (a) vertical stress on mat top (at location of the peak) and, (b) vertical surface acceleration along track center line in between the sleepers $[K=1]$
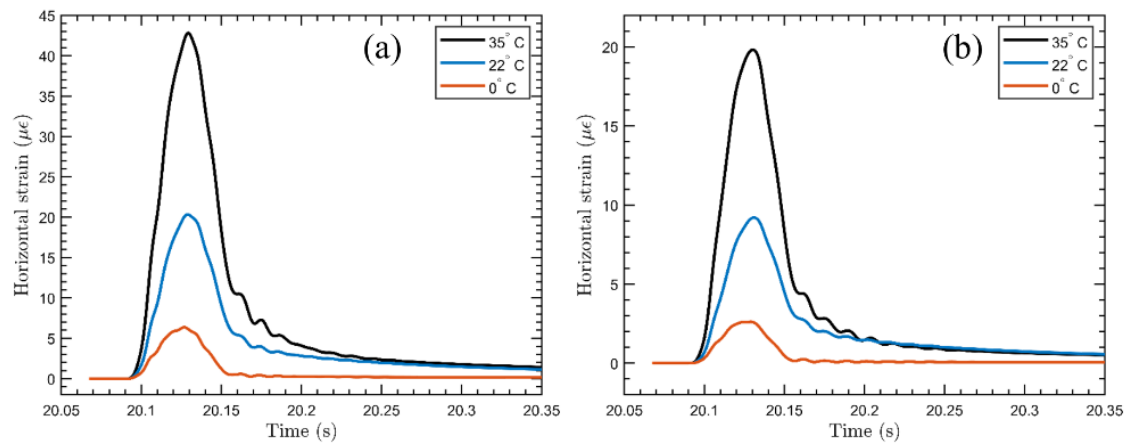

Fig. 6 (a) Influence of temperature on time history of tensile strains at bottom of asphalt layer (at locations of peak strains) along: (a) $\mathrm{Z}$ direction, (b) $\mathrm{X}$ direction $[K=1]$

The sensitivity of the same responses to the variation of the parameter $K$ is presented in Figs. 7 and 8 (assuming, $T=22^{\circ} \mathrm{C}$ ). Fig. 7a illustrates a mild influence of $K$ on the peak vertical compressive stresses occuring below the UGL, (i.e., on top of the mat). The 
vertical acceleration histories shown in Fig. $7 \mathrm{~b}$ depicts high sensitivity to $K$, decreasing by around $60 \%$ with an increase in $K$ from 1 to 8 . This would be attributed to lower vertical displacements caused by a stiffer UGL with increasing $K$. The natural frequency of vibration increases to about $90 \mathrm{~Hz}$ when $K=8$. The influence of $K$ on the horizontal tensile strains at the bottom of the asphalt layer are shown in Fig. 8. The strains are moderately sensitive to $K$; decreasing by about $25 \%$ with an increase of $K$ from 1 to 8 .
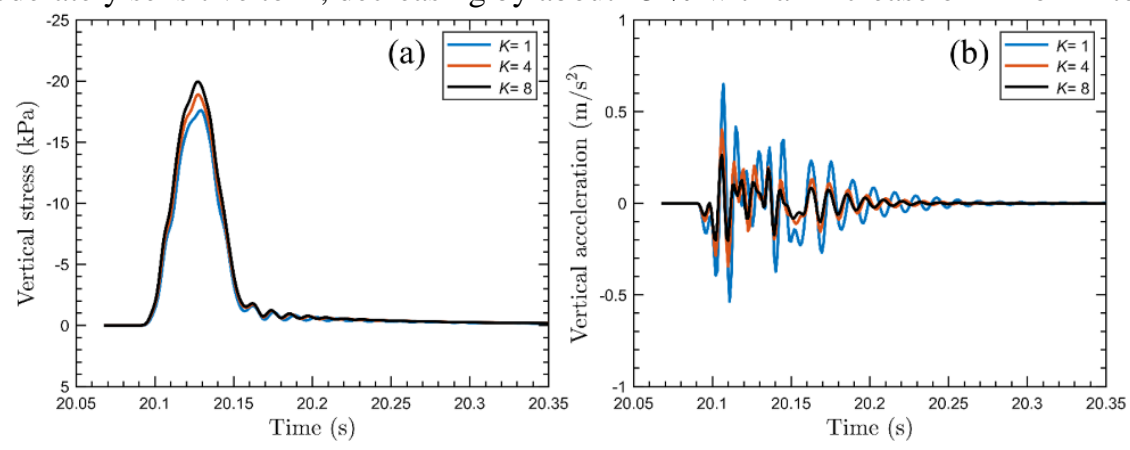

Fig. 7 Influence of initial stresses in the UGL on time history of: (a) vertical stress on mat top (at location of the peak) and, (b) surface acceleration along track center line in between the sleepers [ $T=22$ $\left.{ }^{\circ} \mathrm{C}\right]$
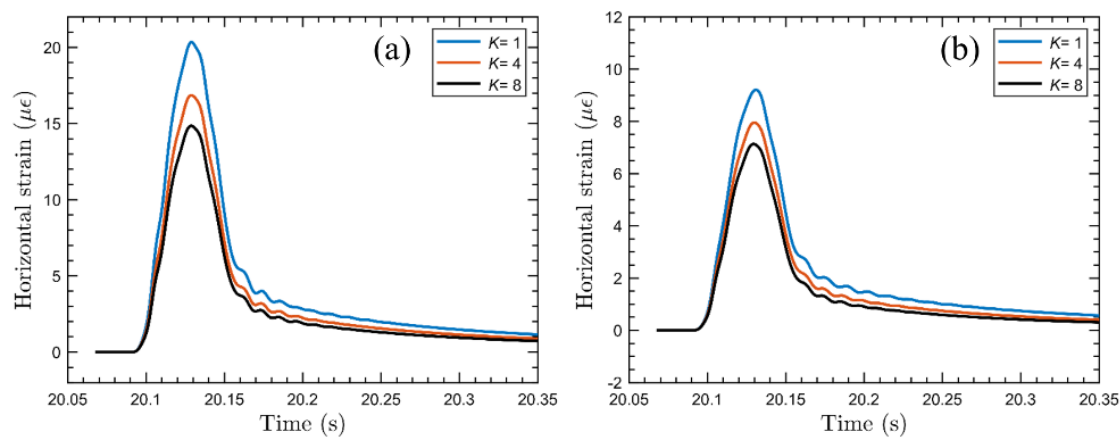

Fig. 8 Influence of initial stresses in the UGL on time history of tensile strains at bottom of the asphalt layer (at locations of strain peaks) along: (a) $\mathrm{Z}$ direction, (b) $\mathrm{X}$ direction $\left[T=22^{\circ} \mathrm{C}\right]$

\section{Conclusions}

A 3-D FE model of asphalt-based track was developed in this study, and dynamic analyses were performed for a vertical pulse load. A parametric study was conducted to investigate the sensitivity of selected model responses to the change in temperature and the initial compaction induced horizontal stresses in the UGL. The findings can be summarized as: (a) the horizontal tensile strains at the bottom of the asphalt layer are highly sensitive to the temperature and moderately sensitive to the initial modulus of the UGL; (b) the vertical stresses at the bottom of the UGL are also quite sensitive to temperature 
but less influenced by the initial modulus in the UGL; and (c) the vertical surface accelerations are found to be sensitive to both the change in temperature and the initial modulus of the UGL.

Acknowledgements The activity presented in the paper is part of the research grant from Innovations fund Denmark, 'Roads2Rails: Innovative and cost-effective asphalt based railway construction system' (Grand Solutions 5156-00006B).

\section{References}

Auersch, L. (1996). Dynamic plate-soil interaction—finite and infinite, flexible and rigid plates on homogeneous, layered or Winkler soil. Soil Dynamics and Earthquake Engineering, 15(1), 51-59.

Galvín, P., Romero, A., \& Domínguez, J. (2010). Fully three-dimensional analysis of high-speed train-track-soil-structure dynamic interaction. Journal of Sound and Vibration, 329(24), 5147-5163.

Huang, Y.H., Rose, J.G., \& Khoury, C.J. (1987). Thickness design for hot-mix asphalt railroad trackbeds (with discussion). In Association of Asphalt Paving Technologists Proc. (56).

Knothe, K., \& Wu, Y. (1998). Receptance behaviour of railway track and subgrade. Archive of applied mechanics, 68(7-8), 457-470.

Lee, S.H., Choi, Y.T., Lee, H. M., \& Park, D.W. (2016). Performance evaluation of directly fastened asphalt track using a full-scale test. Construction and Building Materials, 113, 404-414.

Lee, S.H., Park, D.W., Vo, H.V., \& Fang, M. (2019). Analysis of asphalt concrete track based on service line test results. Construction and Building Materials, 203, 558-566.

Poveda, E., Rena, C.Y., Lancha, J.C., \& Ruiz, G. (2015). A numerical study on the fatigue life design of concrete slabs for railway tracks. Engineering structures, 100, 455-467.

Powrie, W., Yang, L.A., \& Clayton, C.R. (2007). Stress changes in the ground below ballasted railway track during train passage. Proceedings of the Institution of Mechanical Engineers, Part F: Journal of Rail and Rapid Transit, 221(2), 247-262.

Rose, J.G., \& Souleyrette, R.R. (2014). Hot-mix asphalt (bituminous) railway trackbeds: in-track tests, evaluations, and performances-a global perspective: Part III-US asphalt trackbed applications and practices. The 3rd International Conference on Transportation Infrastructure, CRC Press, Pisa, Italy, 2014.

Seed, H.B., Mitry, F.G., Monismith, C.L., \& Chan, C.K. (1967). Prediction of flexible pavement deflections from laboratory repeated-load tests, NCHRP Report 35, Transportation Research Board, Washington DC, USA.

Vostroukhov, A.V., \& Metrikine, A.V. (2003). Periodically supported beam on a visco-elastic layer as a model for dynamic analysis of a high-speed railway track. International Journal of Solids and Structures, 40(21), 5723-5752.

Yang, E., Wang, K.C., Luo, Q., \& Qiu, Y. (2015). Asphalt concrete layer to support track slab of high-speed railway. Transportation Research Record, 2505(1), 6-14. 